\title{
Errata
}

JOURNAL OF MATERIALS SCIENCE, VOLUME 30, NUMBER 17 (1995) 4435-4445

\section{Titanium dioxide induced failure in polycarbonate}

\author{
K. M. BLACKWOOD et al.
}

Figures 6 and 10 were labelled incorrectly and the correct versions are printed below:

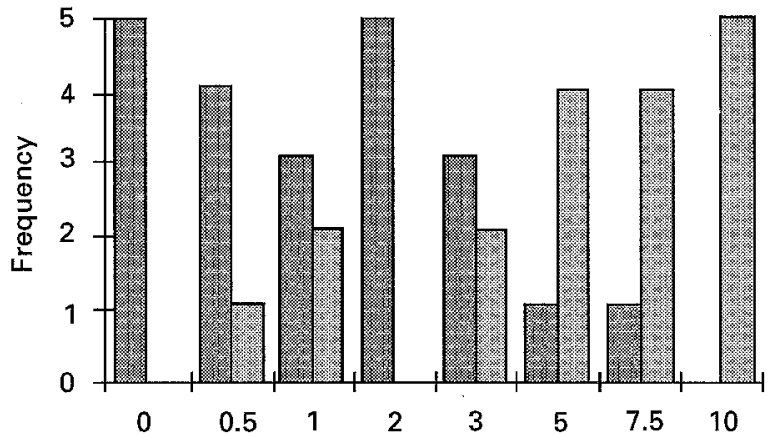

(a)

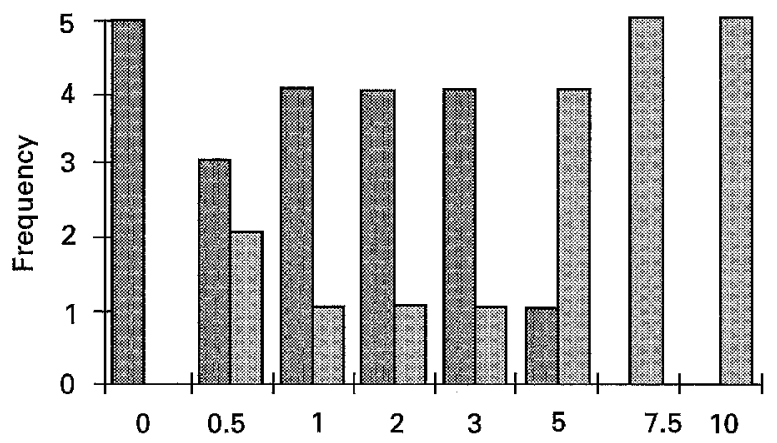

(b)

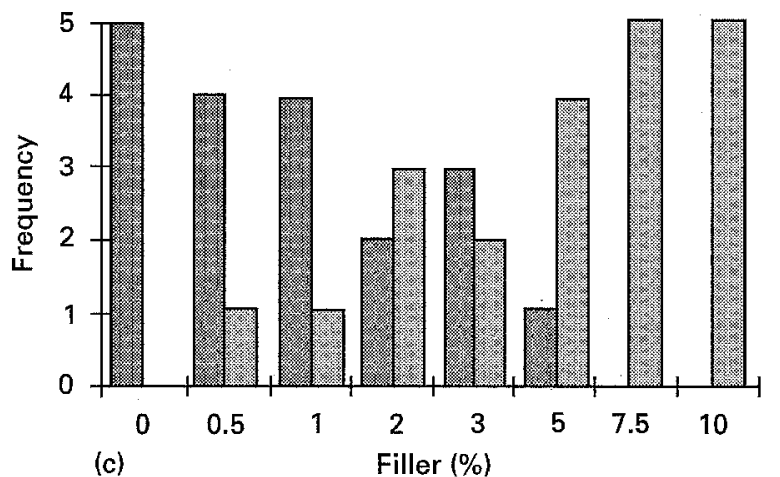

(c)

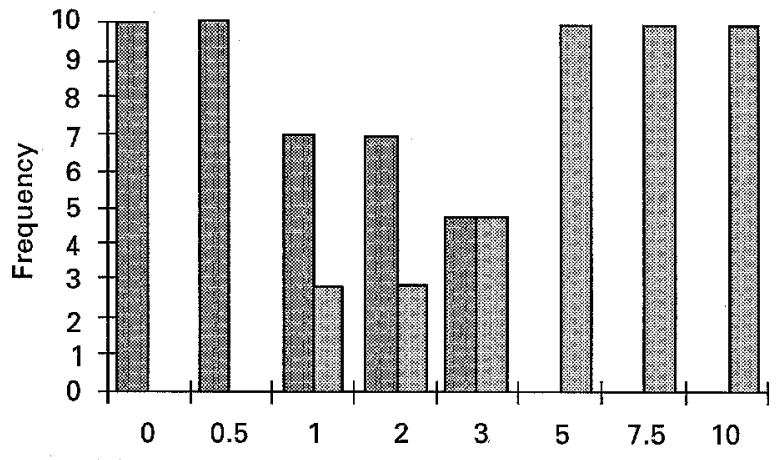

(a)

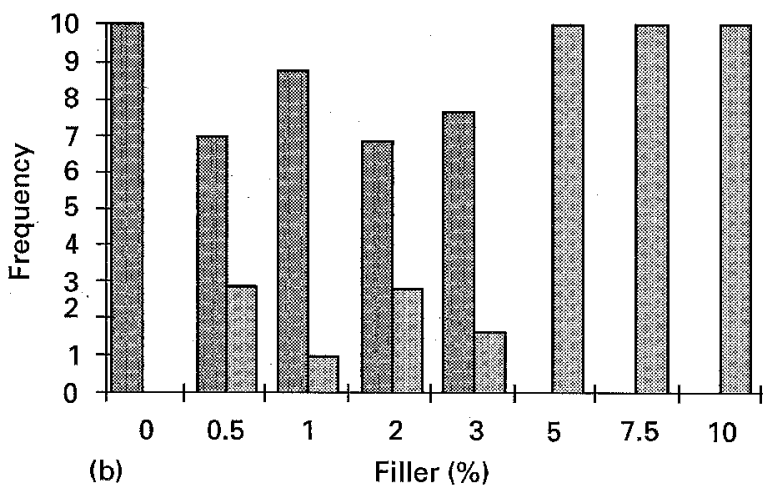

Figure 10 Histogram illustrating the distribution of $(\square)$ ductile and (圆) brittle failures in the impact tests of dried PCD (a), dried PCA (b).

Figure 6 Histogram illustrating the distribution between (圈) ductile and (⿴囗大) brittle failures in the mechanical tests of dried PCD (a), PCA (b) and dried PBT (c). 